\title{
A Competence-based System for Recommending Study Materials from the Web (CBSR)
}

\author{
Athitaya Nitchot, Lester Gilbert, Gary B Wills \\ Learning Society Lab, School of Electronics and Computer Science \\ University of Southampton, Highfield \\ Southampton, SO17 1BJ, United kingdom \\ \{an08r, lg3,gbw\}@ecs.soton.ac.uk
}

\begin{abstract}
A pedagogically-informed approach to the design of an e-learning system is important since an effective learning system requires teaching activities that match the students' learning requirements. Currently some e-learning systems are based on adaptive educational hypermedia. User modelling is one of the components of adaptive hypermedia. However, currently designed user models are inconsistent in estimating learner's knowledge level, are not pedagogically designed, and do not satisfactorily incorporate the achieved learning of the learner. The paper proposes a competency-based system for recommending study materials from the Web to learners (CBSR), and explores the benefits of a competency model for an improved pedagogical approach to e-learning and a more consistent profile of learners' competences which can persist though their learning life. A competences structure is represented as a directed acyclic graph (DAG), and the paper considers the processing of a competence structure to identify learners' existing/desired competences and provide appropriate study materials from the Web.
\end{abstract}

Keywords - competency model, user model, webbased education, lifelong learning, adaptive hypermedia

\section{INTRODUCTION}

The paper considers the design of an e-learning system which recommends appropriate study materials from the Web without requiring teacher intervention. Designing an educational technology solution and an elearning system requires an understanding of the pedagogical issues, discussed in section 2 .

Currently the design of an e-learning system could be based on an Adaptive Hypermedia approach. However, there are problems with the learner model or user model which is one of components in an Adaptive Hypermedia architecture. The problems are inconsistency in estimating a learner's knowledge level, not supporting a pedagogy approach, and inadequate support for lifelong learning. These issues are explored in section 3 .

The problems with user modeling could be solved by employing a competency model within the system's design. The details and benefits of a competency model are described in section 4. For our system design (outlined in section 5), we consider two types of competences: current/existing and desired. The current or existing competence is the estimation of the actual competence of the learner. The desired competence refers to the learner's intended learning outcome or the competence which the learner wishes to gain.

After the existing and desired competences of the learner are established, we explore processes for deriving recommended study materials and identify three possibilities. Section 6 illustrates a prototype implementation of one possibility, including the associated database and user interface. Section 7 discusses the direction of future work and provides some conclusions.

\section{Pedagogy}

In order to construct or design an effective elearning system, we should consider the pedagogical approach that will support such an e-learning system and provide the strategies for designing a successful system. Pedagogy can be defined as the art of teaching and refers to strategies, methods, and styles of instruction [1]. It consists of behaviours or activities designed to impart knowledge in the process of teaching and learning [2]. Consideration of pedagogy underlies the proposed system with its emphasis on supporting learners to achieve their intended learning outcomes.

The 'learning transaction' (figure 1) refers to the lowest unit of analysis in learning and teaching [3]. A learning transaction is a generalisation from 
Laurillard's conversational model [4] which describes the learning and teaching environment in higher education. An essential component of a learning transaction is its purpose which is implied from the aim of the overall learning and teaching transaction. The purpose indicates the learner motivation and it will be the objective of the e-learning development including the use of any learning materials or teaching assets [3].

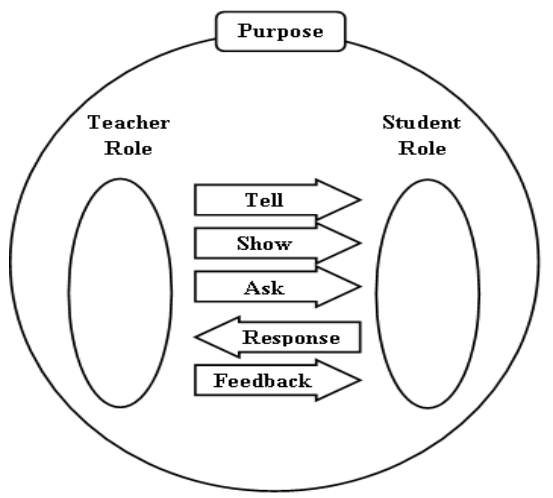

Figure 1: Learning Transaction [3]

There are two roles in a teaching and learning situation: teacher and student. The learning transaction provides five keys exchanges: tell, show, ask, response and feedback. The consideration of these exchanges will aid the analysis and design of effective learning and teaching situations.

\section{CURRENT Designs For USER MODELING}

The current design of User Modelling - a component of Adaptive Hypermedia - has been shown to have some problems, including inconsistency in estimating the learner's knowledge, lack of support for the explicit specification of the ability of the learner, and lack of support for lifelong learning. These problems follow from the system design that is based on traditional adaptive hypermedia user models.

\section{A. Overview of User Modelling}

The user model in Adaptive Hypermedia is one of the important components in adaptive hypermedia architecture. The user model is known historically as a user profile, and also known as the student model in Intelligent Tutoring Systems (ITS) [8]. The user model represents the level of the user's knowledge and behaviour that effect their learning and performance [9]. Adaptive systems use user models in order to adapt their content and navigational possibilities to their particular users. There are six popular fields in which the user is modelled: knowledge, interests, goals, background, individual traits, and context of work [10] The first five fields have been focused on for many years but the context of the user's work is a relatively new research direction within AHS. This can be considered as user location, physical environment, social context and affective state [10].

User models are generally distinguished into two main categories, 'overlay' and 'stereotype' [11]. By overlay modelling, the user's state of knowledge is described as a division of the expert's knowledge in that domain [9]. The user is described through a set of attributes-value pairs where values are quantitative such as percentage or qualitative such as good and excellent. Stereotype user modelling attempts to cluster all possible users of an AHS into several groups. All users in the same stereotype will be treated in the same adaptation techniques [10]. A stereotype user modelling approach categorizes the users into stereotypes (such as novice, intermediate, advanced, or expert) or a group of users that have a common characteristics attribute [11].

\section{B. Drawbacks of AH User Modeling}

Kobsa [12] notes that AH user modelling components draw mostly on assumptions about the user, which may not necessarily be correct. Such user modelling inherently involves the risk of misunderstandings. In addition, the authoring process for creating the user model is a complex task, and there are no standardized approaches to adaptive techniques in the system. Sitthisak et al [13], highlighted similar problems for adaptive assessment, for example, the inconsistency of adaptive assessment systems in estimating a learner's knowledge level.

A significant problem is the issue of supporting lifelong learning in adaptive hypermedia and assessment systems because of difficulties in updating rules, content and assessment within such systems. To briefly explain this problem, we can consider the scenario of a learner using an AHS. We imagine the learner starts with a desire to gain a new or improved competence. The AHS provides the relevant study materials and the learner ideally gains that competence. If the same learner uses the system again and wishes to gain another competence then the user modelling in AHS typically does not provide materials which are as relevant for the next competence, because it does not know that the learner has completed the previous competence. In other words, when the learner reuses the adaptive system, it typically does not update its user model with respect to the recently-gained competence.

In addition, the estimation of a learner's knowledge in current user models does not readily render it compatible with an interoperable format and this then leads to problems supporting lifelong learning. Hence, it is very challenging for developers to overcome these problems by designing a better model using the same underlying approach. 


\section{COMPETENCY MODEL}

This section introduces a competency model intended to address the problems of lack of support for lifelong learning, inconsistency in estimating the learner's knowledge, and unsatisfactory incorporation of the user's achieved learning.

The word "competency" refers to the ability to do a particular activity to a prescribed standard [14]. The concept of competence has been associated with an education system [15] and professional development [16]. In professional development, competences are considered as a criterion to select the most appropriate available person for a given task [16]. In the education system, competence could be used to describe final attainment levels of educational programs [15].

\section{A. COMBA Competency Model}

The proposed model for this paper draws on the multi-dimensional 'COMBA' competency model from Sitthisak, Gilbert and Davis [17]. This considers the learners' "learned capability" instead of their "knowledge level" and considers competencies and learned capabilities as a multidimensional space [17]. The COMBA model consists of three major components: subject matter, capability, and context (figure 2).

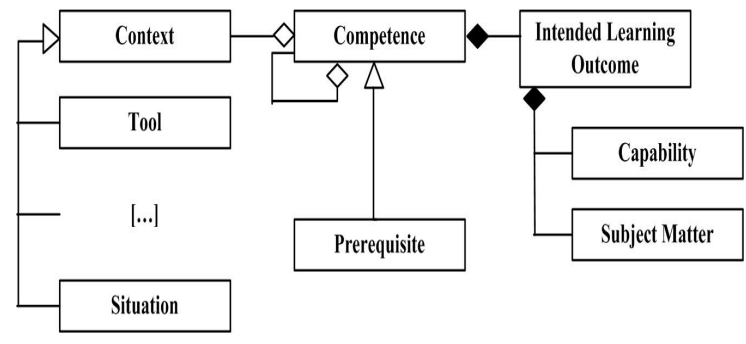

Figure 2: COMBA Competency Model [17]

\section{B. Pedagogical Support with COMBA Competency Model}

The consideration of pedagogy is essential for this paper as it underlies the proposed system with its emphasis on supporting the learner to achieve their intended learning outcomes. An intended learning outcome comprises two key elements: a statement of the topic or subject matter, and a statement of the learner's capability with respect to such subject matter. From figure 2, it is obvious that the COMBA model incorporates the intended learning outcomes which can be formally described as the composition of 'capability' and 'subject matter'. 'Capability' indicates what the learner will be able to do with the subject matter of the e-learning objectives. Hence the COMBA model supports the pedagogical approach of the learning transaction.
In addition, the COMBA model incorporates the idea of 'context' in characterising a competence. Learners may have differing levels of proficiency in a given intended learning outcome depending upon the context of their performance. A typical example of the profound importance of context is often seen during medical training, where a doctor might be being taught how to undertake an appendectomy. One context might be a well-equipped operating theatre in a major hospital; another might be in a tourist aeroplane cruising at 10,000 metres in the middle of the Pacific.

Importantly, the COMBA model gives consistency in recording the learner's level of performance, as these levels are usually carefully specified in terms of the learner's capability and in terms of the context in which the performance is to be demonstrated. The implementation of such a competency model in the proposed system concentrates on the learner's capability and not on their 'knowledge level', which is difficult to properly characterise or estimate in the absence of associated learner capability or context.

Consistency in recording the learner's level of competency leads to significant advantages in using the proposed system for lifelong learning, particularly when coupled with the ability of the competency model to be rendered in an interoperable form; for example by using COMBA extensions to IMS RDCEO [18] or HR-XML [19]. Such a system allows the learner to use the system anytime throughout his/her life where learners with different competence levels can obtain materials tailored according to their own competences without the need to restart from the same competence level again.

\section{SYSTEM DESIGN}

This section discusses a system design which suggests appropriate study materials links from the Web to a learner based on his/her competences. The design illustrates how the system deals with learner competences and how it provides appropriate study materials as links from the Web to learners. The design also considers a competence structure appropriate to a particular knowledge domain including the competence node relationships. Finally this section discusses each step within the system process and how they traverse the competence structure.

\section{A. Process within the System}

The overview of the process within the system design, illustrated figure 3, shows how the system deals with learners' competences and how it provides appropriate study materials links from the Web to learners so that learners can achieve their intended learning outcomes. 


$\begin{gathered}\text { Learner's } \\ \text { competences }\end{gathered}$ Keywords $\square \begin{gathered}\text { Google } \\ \text { Search }\end{gathered}$
$\square$ Links $\square$ Indicate the steps of the process within the system
Competences

Figure 3: Overview of Process within the System

For this research, there are two kinds of learner competences: desired, and existing competence. Desired competence refers to the learner's intended competence which the learner wishes to gain. The current or existing competence is the estimation of the actual competence of the learner.

First, a sub-process is required to construct a learner's competence structure (section 5.2) so that the system can generate keywords from appropriate competences (section 5.3).

After the keywords are obtained, the system constructs a Google search based on these keywords, and then suggests the resulting links to learners. At the next step, the system suggests the next desired competence to the learner, based on the competence structure.

\section{B. Competence Structure}

Consideration is given initially to one sample of knowledge, the domain of: mathematical factorization including the concepts of common factor and highest common factor (HCF). This knowledge domain has a well-known structure, is easily understood and is relatively uncomplicated. The subject matter comprises 'factor', 'common factor' and 'highest common factor'. The capabilities associated with the subject matter include 'evaluate', 'calculate' and 'define'. Table 1 shows the resulting competences, their identification numbering, and their corresponding capability and subject matter content.

\section{TABLE I. LIST OF COMPETENCES}

\begin{tabular}{|c|c|c|}
\hline $\begin{array}{c}\text { Competency } \\
\text { Number }\end{array}$ & Capability & Subject Matter Content \\
\hline C01 & Evaluate & Highest Common Factor \\
\hline C02 & Evaluate & Common Factor \\
\hline C03 & Evaluate & Factor \\
\hline C11 & Calculate & Highest Common Factor \\
\hline C12 & Calculate & Common Factor \\
\hline C13 & Calculate & Factor \\
\hline C21 & Define & Highest Common Factor \\
\hline C22 & Define & Common Factor \\
\hline C23 & Define & Factor \\
\hline
\end{tabular}

The competences in table 1 may be structured into a directed acyclic graph (DAG) [20] representation (figure 4). A DAG is an appropriate structure for the competences in the HCF knowledge domain. Firstly, there is no root node (or one highest node) in a DAG, and this corresponds to the HCF domain since we cannot locate $\mathrm{C} 03, \mathrm{C} 02$, or $\mathrm{C} 01$ as the root node for the competence structure. Secondly, a DAG allows a relatively free structure which means that every node can connect to those other nodes as may be required to express their knowledge dependencies.

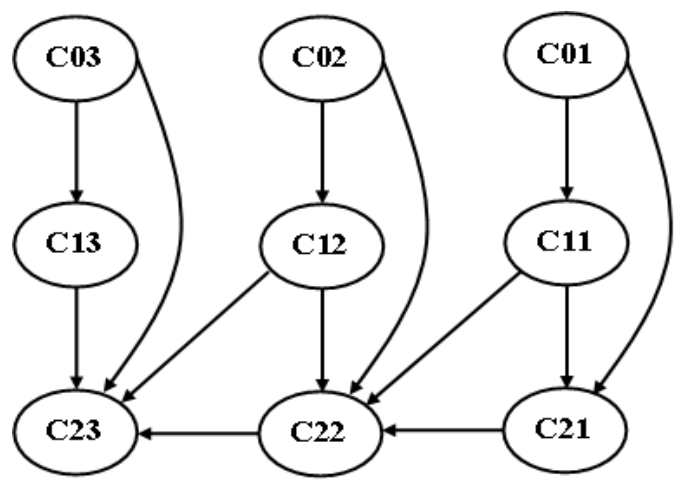

Figure 4: DAG Representation for Competences in $\mathrm{HCF}$, Common Factor, and Factorization

The competence structure of figure 4 may be considered an activity network, where each node represents a competence to be completed and the directed edges refer to the next competence that needs to be completed. There are three nodes that have no parents $(\mathrm{C} 03, \mathrm{C} 02$, and $\mathrm{C} 01)$ and there is just one leaf node (C23). The parent-child relationship between competence nodes can be illustrated by considering the example of $\mathrm{C} 02$. In order to achieve competence $\mathrm{C} 02$, a learner must complete $\mathrm{C} 12$ and $\mathrm{C} 22$ beforehand. To attain $\mathrm{C} 12$, a learner must complete $\mathrm{C} 23$ and $\mathrm{C} 22$. To achieve $\mathrm{C} 22$, the learner must firstly achieve $\mathrm{C} 23$.

\section{Processing the Competence Structure}

From the system processes of figure 3, there are three procedures which deal with the competence structure:

1) Obtain desired and existing competences from the learner

2) Generate the search terms from desired and existing competences

\section{3) Recommend next competence}

There are three possible approaches for processing the competence structure.

\section{1) Approach A (Go Straight to Desired Competence)}

a) Obtain desired/existing competences from the learner

The system begins by providing a choice of desired competences to the learner. Learners who do not have any history of using the system previously get a full list of competences. Learners who have some history of 
using the system get a list of the competences they have not visited before. Next, a list of existing competences is automatically generated by the system, containing child (including children of child) nodes of the desired competence.

b) Generate the search terms from desired/existing competences

The system sets the desired competence sentence (capability with subject matter) as a search term and then adjusts it with reference to existing competences. Adjustment uses the Google search symbols "+" and "", by adding "+" in front of the desired competence terms and adding "-" in front of terms from existing competence statements. The intention is yield search results that contain only links to the desired competence and that omit links related to existing competences. The search results should be links to appropriate study materials which a learner needs or desires and not to what they already have learned or achieved.

\section{c) Recommend next competence}

The next desired competence is selected from a list of parent (or including parent of parent) nodes of the previously desired competence.

\section{2) Approach B (Go Only Adjacent Nodes)}

a) Obtain desired/existing competences from the learner

The system begins by providing a choice of existing competences to learners. Learners who have not logged into the system before get a list of all competences. Learners who have some history of using the system get a list of the competences which they have never visited before and the competences they have previously desired. Next, a list of desired competences is automatically generated by the system, being the adjacent parent nodes of existing competences.

b) Generate the search terms from desired/existing competences

As for approach A.

c) Recommends next competence

The next desired competence is selected from a list of adjacent parent nodes of previously desired competences.

3) Approach C (Go Along and Go Up and Go Along)

a) Obtain desired/existing competences from the learner

As for approach A.

b) Generate the search terms from desired/existing competences
The system computes the gap between the desired competence and the existing competences. A gap is a route from the desired to the existing competence, and the required search terms are generated from the nodes in the gap. The consideration of the 'best' route is currently an item of future work.

\section{c) Recommend next competence}

As for approach A.

\section{IMPLEMENTATION}

This section illustrates an implementation of a prototype based on the discussion of system design in section 5, first illustrating the design of the database for a competence structure, and then illustrating the user interface.

At this initial stage of the research, approach B was implemented as it was easy to develop and concerned only adjacent nodes (no gaps between existing and desired competences). In approach $\mathrm{A}$, the gap between the two competences is ignored, and this could be problematic if there are several nodes in one gap. Learners may need to learn some competences in a gap before reaching the desired competence. Approach $\mathrm{C}$ explicitly addresses the gap between desired and existing competence, but the nature of the 'best' gap or route has not yet been explored. This will be considered and explored further in future research.

\section{A. Competence Structure Database}

The DAG representation of competences in the factorization domain (figure 4) consists of pairs of edges and nodes. Correspondingly, the database is constructed based on node pairs. One database table stores the relationship between node pairs, where each record contains the details of one edge and two nodes. The table requires just one attribute called 'CompID' which indicates a parent node for particular edge, and a second attribute called 'ChildID' which indicates the child node. Figure 5 shows a screenshot of the 'Compchild' table in a MySQL database.

\begin{tabular}{|c|c|c|c|c|}
\hline \multicolumn{3}{|c|}{$\leftarrow \mathrm{T} \rightarrow$} & ComplD & ChildID \\
\hline$\Gamma$ & $\Rightarrow$ & $x$ & C13 & $\mathrm{C} 23$ \\
\hline$\Gamma$ & $\theta$ & $x$ & $\mathrm{C} 03$ & C13 \\
\hline$\Gamma$ & 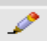 & $x$ & $\mathrm{C} 03$ & $\mathrm{C} 23$ \\
\hline$\Gamma$ & $\Leftrightarrow$ & $x$ & $\mathrm{C} 01$ & $\mathrm{C} 21$ \\
\hline$\Gamma$ & $\Rightarrow$ & $x$ & $\mathrm{C} 01$ & C11 \\
\hline$\Gamma$ & $\theta$ & $x$ & $\mathrm{C} 02$ & C12 \\
\hline$\Gamma$ & 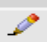 & $x$ & $\mathrm{CO} 2$ & $\mathrm{C} 22$ \\
\hline$\Gamma$ & $\theta$ & $x$ & C12 & $\mathrm{C} 23$ \\
\hline$\Gamma$ & $\rho$ & $x$ & C12 & $\mathrm{C} 22$ \\
\hline$\Gamma$ & $\theta$ & $x$ & C11 & $\mathrm{C} 22$ \\
\hline$\Gamma$ & 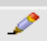 & $x$ & C11 & $\mathrm{C} 21$ \\
\hline$\Gamma$ & $\Rightarrow$ & $x$ & $\mathrm{C} 22$ & $\mathrm{C} 23$ \\
\hline$\Gamma$ & 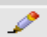 & $x$ & $\mathrm{C} 21$ & $\mathrm{C} 22$ \\
\hline
\end{tabular}

Figure 5: Table of Competences Relationship (Compchild Table) 


\section{B. Interface}

The user interfaces were designed and coded with Html and PHP, allowing a learner to choose their desired and existing competences using radio boxes. The lists of desired and existing competences were obtained from the database of the competence structure. The processes dealing with the competence structure were derived according to approach B (see section 5.3.2).

An existing competence page (figure 6) allowed a learner to choose existing competence or 'what he/she already knows' from the provided radio boxes. The system generated the list of existing competences based on approach B.
The desired competence page (figure 7) allowed the learner to choose his/her desired competence from the list, automatically generated by the system, containing adjacent parent nodes of a previously chosen competence.

From the chosen desired and existing competences, the system generated the search terms (figure 8). The search terms were the words from the chosen desired competence, adjusted for existing competences using the Google search symbols "+" and "-.".

Finally, the system suggested a next desired competence for a learner (figure 9) as a list of adjacent parent nodes of previously desired competences.

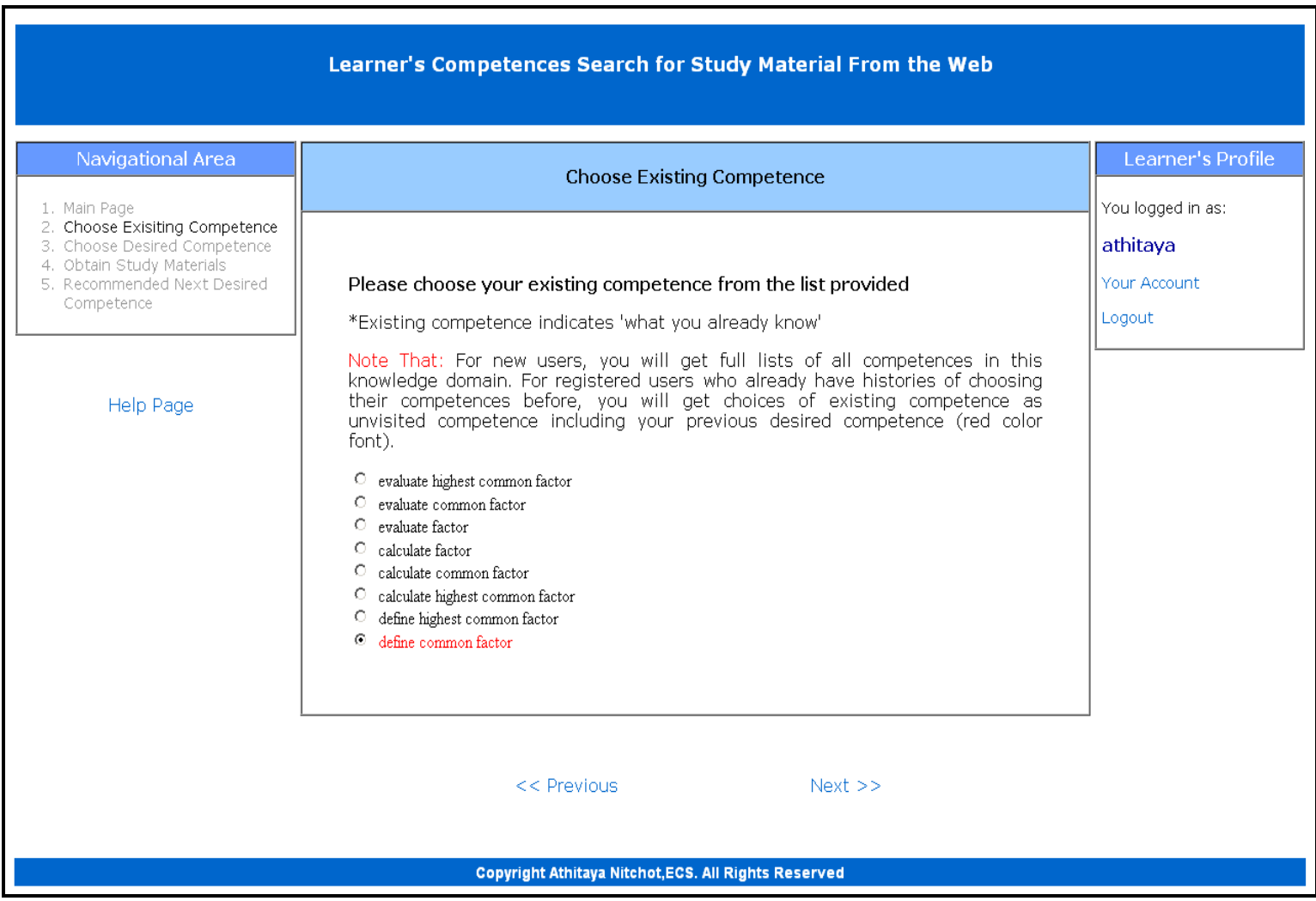

Figure 6: Screenshot of Existing Competence Page 


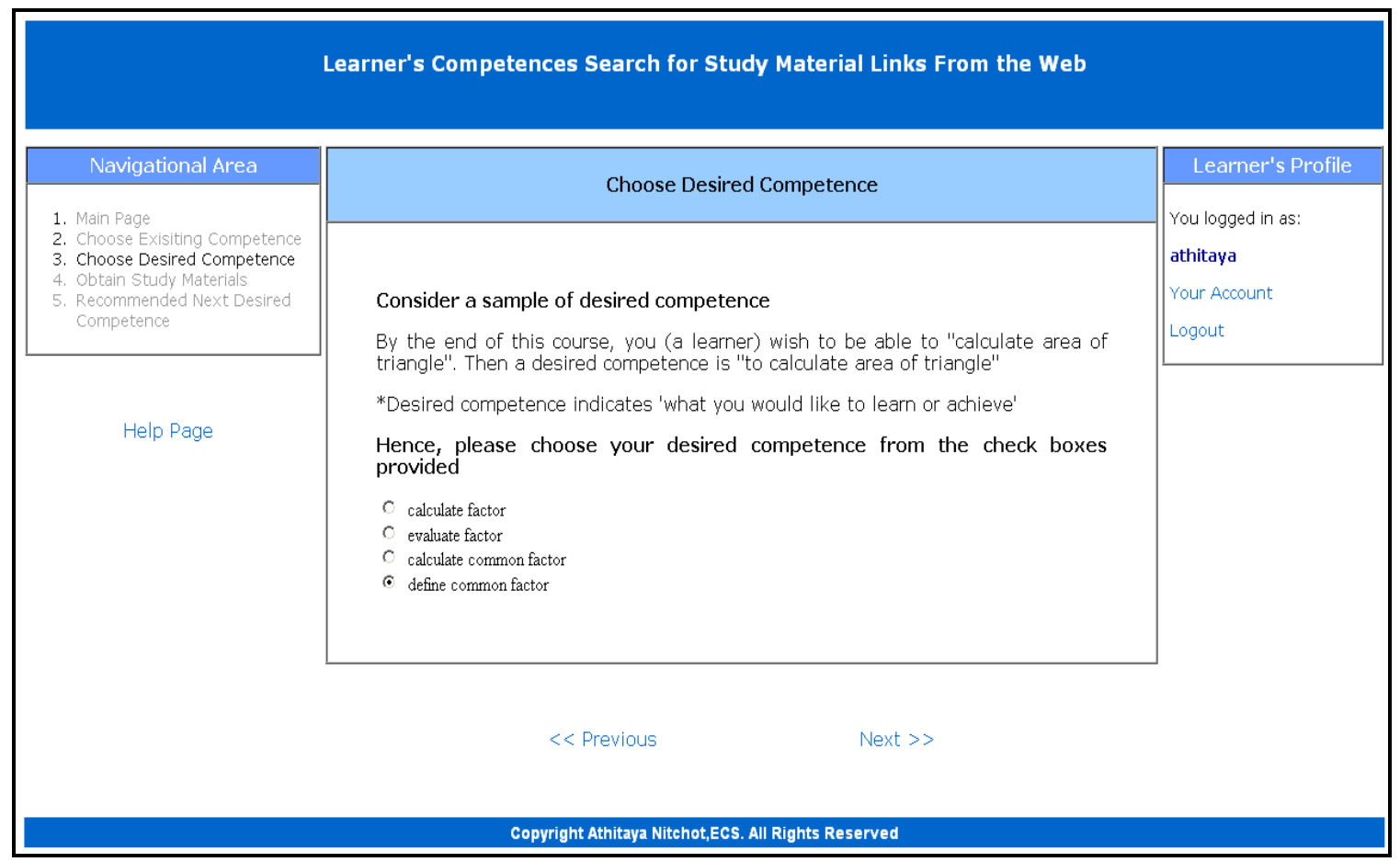

Figure 7: Screenshot of Desired Competence Page

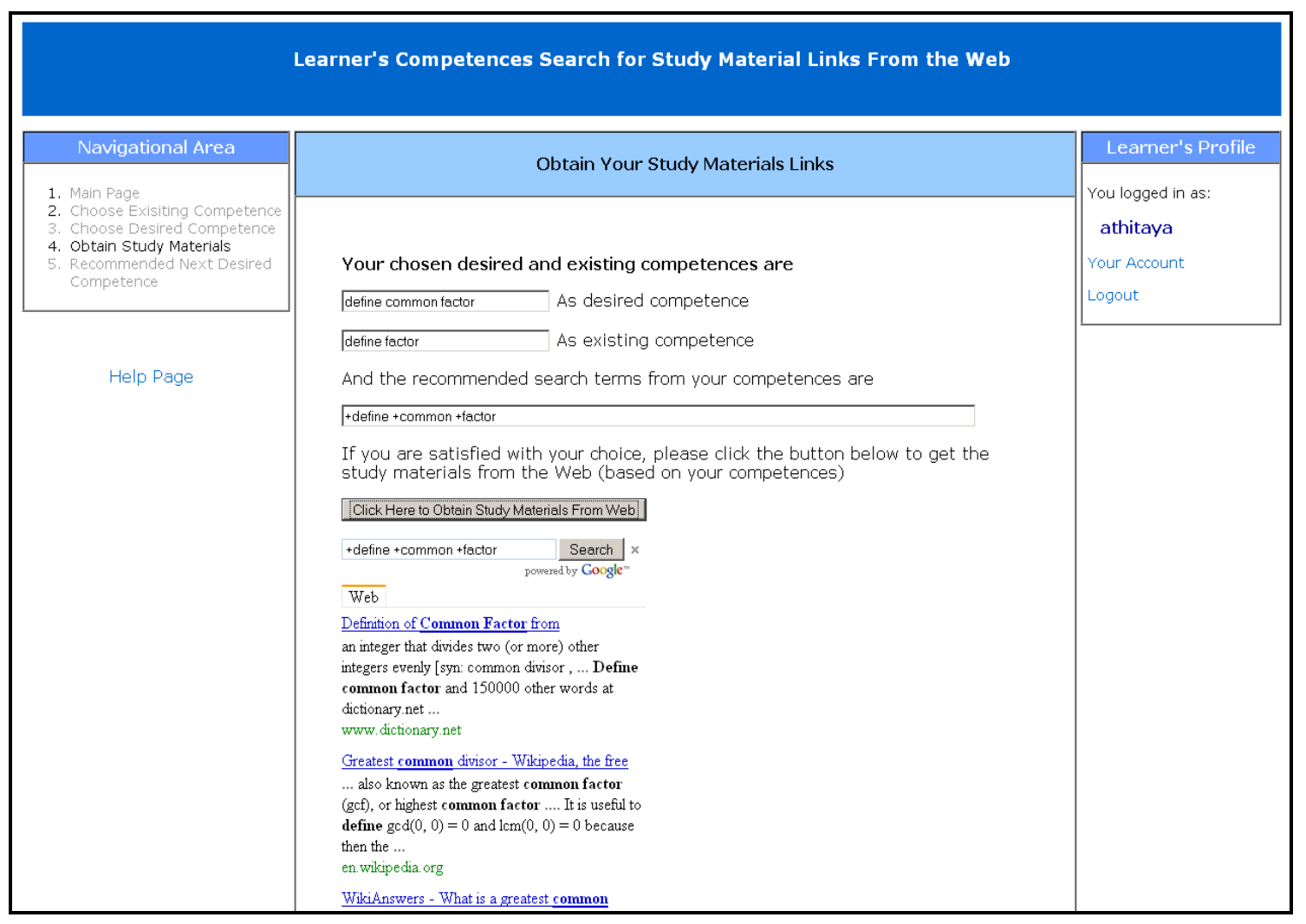

Figure 8: Screenshot of Study Materials Links Page 


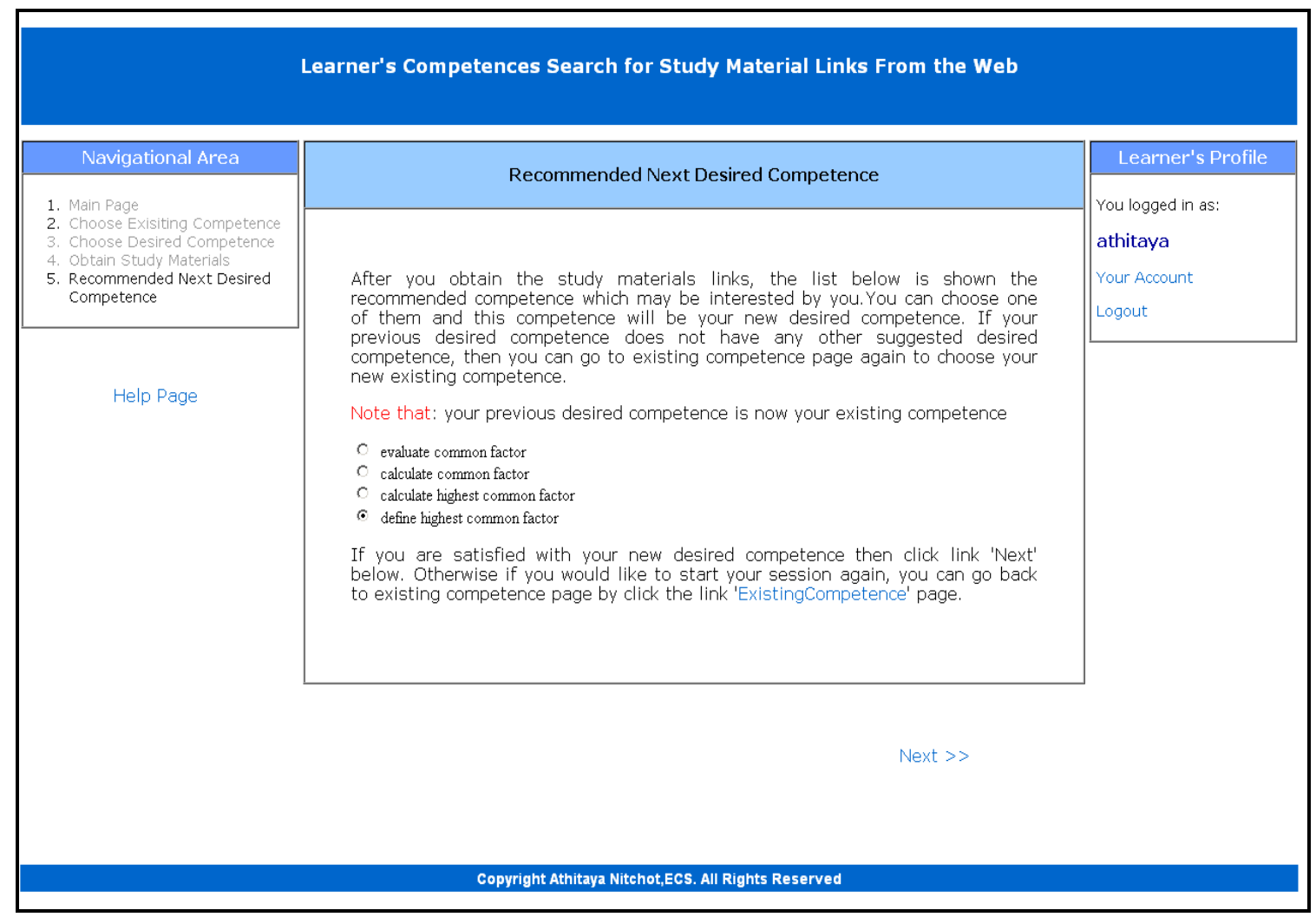

Figure 9: Screenshot of Next Desired Competence Page

\section{CONCLUSION AND FUTURE WORK}

This paper proposes a design for a system for recommending appropriate study materials as links from the Web to the learner without any communication from a teacher. The design conceptualises an approach to solve some problems in AHSs of a user model which is inconsistent in estimating a learner's knowledge level, does not conceptualise the learner's intended learning outcome, and is not generally able to support lifelong learning. The resulting design involves the COMBA competency model which gives the benefit of consistency with pedagogical approaches within elearning systems. The paper discusses some approaches for deriving recommended study materials based upon the chosen and illustrates the implementation of one approach (B).

The direction of future work for this research will include implementations of approaches $\mathrm{A}$ and $\mathrm{C}$ in processing a competence structure. Other knowledge domains will be considered to illustrate different competence structures. Finally, evaluations are needed to show whether learners can successfully obtain appropriate study materials as Web links Web based on their desired and existing competences.

\section{REFERENCES}

[1] J. Leach and B. Moon, Learners \& Pedagogy: Paul Chapman Educational Publishing, 2000.

[2] W. N. Mehanna, "e-Pedagogy: the pedagogies of e-learning " in Networked Learning Conference 2004 Proceedings, The University of Lancaster, 2004.

[3] L. Gilbert and V. Gale, Principles of E-learning Systems Engineering. Oxford, UK: Chandos Publishing, 2008.

[4] D. Laurillard, Rethinking university teaching : a framework for the effective use of educational technology 2 nd ed. London: Routledge, 1993.

[5] M. D. Merrill, Instructional Design Theory. New Jersey: Educational Technology Publication, 1994.

[6] B. S. Bloom, Taxonomy of Educational Objectives, Handbook I. New York: David McKay Co Inc., 1956.

[7] R. F. Mager, Preparing instructional objectives Atlanta: Center for Effective Performance, 1997.

[8] M. C. Polson and J. J. Richardson, "Foundations of intelligent tutoring systems," L. Erlbaum Associates Inc., 1988.

[9] A. Kavcic, "The role of user models in adaptive hypermedia systems," in Electrotechnical Conference, 2000. MELECON 2000. 10th Mediterranean, 2000, pp. 119-122 vol.1. 
[10] P. Brusilovsky and E. Millán, "User Models for Adaptive Hypermedia and Adaptive Educational Systems," in The Adaptive Web, 2007, pp. 3-53.

[11] M. Cannataro and A. Pugliese, "A survey of architectures for adaptive hypermedia," in Web Dynamics M. Levene and A. Poulovassilis, Eds., 2004.

[12] A. Kobsa, "User modeling: Recent work, prospects and Hazards.," Adaptive User Interfaces: Principles and Practise, 1993.

[13] O. Sitthisak, L. Gilbert, and H. C. Davis, "Towards a competency model for adaptive assessment to support lifelong learning," in TENCompetence Workshop on Service Oriented Approaches and Lifelong Competence Development Infrastructures Manchester, UK, 2007.

[14] M. K. Smith, "competence and competency : What is competence? How has it been reduced to competency? What is the impact on education and training?," in Mark K. Smith: Infed (the informal education homepage), 1996.

[15] A. Stoof, R. Martens, and J. van Merriënboer, "Web-based support for constructing competence maps: design and formative evaluation," Educational Technology Research and Development, vol. 55, pp. 347-368, 2007.
[16] M. Eraut, Developing Professional Knowledge and Competence (Paperback). London: Falmer Press, 1994.

[17] O. Sitthisak, L. Gilbert, and H. Davis, "TRANSFORMING A COMPETENCY MODEL TO ASSESSMENT ITEMS " in 4th International Conference on Web Information Systems and Technologies (WEBIST) Funchal, Madeira - Portugal, 2008.

[18] IMS RDCEO, "IMS Reusable Definition of Competency or Educational Objective - Information Model," 2002.

[19] HR-XML, "Competencies (Measurable Characteristics Recommendation)," in HR-XML Consortium, C. Allen, Ed. USA: HR-XML Consortium, 2004.

[20] S. Handley, "On the use of a directed acyclic graph to represent a population of computer programs," in Evolutionary Computation, 1994. IEEE World Congress on Computational Intelligence., Proceedings of the First IEEE Conference on, 1994, pp. 154-159 vol.1. 